US fights Canada on Videotex

Moynihan plans retaliation for

\section{Ottawa law}

\section{Washington}

An international war of nerves between the Canadian government and Senator Daniel Patrick Moynihan (Democrat, New York) may break into the open in September, affecting the fates of the Canadian, British and French videotext and teletext systems now competing for a prime position in the huge US market.

When the Senate's Finance Committee meets in late September, to take up a rather parochial bill dealing with US-Canadian broadcasting relations, it could well adopt a policy that would cripple Canada's videotext system, Telidon, as a contender in the US market - thus improving the chances of Britain's Prestel and France's Antiope, which until now had seemed dim.

The agent provocateur is Moynihan, who announced in June that he would try to introduce a clause into the bill (S.2051) that would prevent the treatment of any monies spent by US businesses to adopt Canada's Telidon system as a business expense. Many major US news organizations, such as Time-Life Inc., are well along the road towards adopting Telidon. Moynihan's clause has been denounced by an association of 100 US companies and individuals, the Videotext--Industry Association, as "an unprecedented and unreasonable kind of trade warfare".

Moynihan's clause is intended as a stick to beat the Canadian government and make it bend on a completely different issue. Moynihan's home state of New York includes several US broadcasting stations near the Canadian boarder that derive large audiences and considerable advertising revenue from Canada. The stations have been up in arms ever since 1976, when the Canadian parliament adopted a law, known as $\mathrm{C} 58$, that attempted to gain "cultural sovereignty" over what is broadcast in Canada. As Canada could not legally prevent incoming broadcasts (which are picked up by cable networks), it used the only legal means at its disposal and deprived Canadian companies of the right to treat as a business expense the cost of advertising on these US stations. The stations promptly called on Washington to do something. They estimate they have lost $\$ 20$ million annually in advertising.

Thus began what is now called the "border broadcaster's war". Both President Jimmy Carter and the office of the US Special Trade Representative have criticized the Canadian action. Congressmen from states along the border

have introduced legislation depriving US companies that advertise on Canadian broadcasting stations of the right to deduct their advertising revenues. But the Senate's bill (S.2051) is an insufficient weapon: the Canadian stations stand to lose only about $\$ 3$ million in advertising revenues, compared to the $\$ 20$ million lost to US stations under the Canadian law.

Thus Moynihan has hit on Telidon as an additional means of bringing Canada to the negotiating table. Canadian engineers worked closely with AT\&T, NBC Inc, RCA Corporation and others to develop the "North American Standard" as a common standard to which all videotext and teletext systems should adhere. A key element in the system is the concept for

\title{
Posts and statutes change at CNRS
}

A close henchman of Jean-Pierre Chevènement, the highly political French minister for research and industry, is to take up the top job in the management of basic science in France - the directorgeneralship of the Centre National de la Recherche Scientifique (CNRS). CNRS has a budget of FF6,000 million ( $£ 500$ million) and a staff of 20,000 , and most French scientists aspire to be supported by it. The appointment and major reforms in the statute of CNRS were announced last week in moves described by the minister as marking a "great change" in French science.

Some people, however, fear an increase in the political control of French science, something the CNRS directorate has long resisted on the principle that scientists are the best managers of science.

Certainly, there are some grounds for concern. Last year, the then president and director-general of CNRS resigned over the issue - when the minister tried to appoint his own nominee as director of social sciences. That post remains unfilled, as Chevènement appeared (remarkably) to have misconstrued the CNRS constitution.

But the constitution is now changed, so that CNRS scientific directors appointed only on the advice of the director general, rather than on his instruction and their powers will be increased in a general devolution of power in the CNRS management.

The new appointee to the CNRS director-generalship, 43-year-old physicist Professor Pierre Papon, denies, however, that the powers of his new post will be reduced. The increase in ministerial power "is only formal" he said on Monday. In practice, there will be constant discussion between CNRS and the ministry "as always". As for the great changes, CNRS will protect basic science, said Papon, but will now take more account of national cultural, economic and social needs.

Further, the powers of the director- drawing graphics that is at the heart of Telidon. AT\&T's own videotext system, which is not as fully developed as Telidon, would be compatible with this standard as would the French Antiope. These and other companies have jointly protested to Moynihan, citing the "severe negative consequences on the development of electronic publishing in the United States".

So far, the Canadian government had refused to be drawn on Moynihan's proposed action against Telidon but Canada will probably protest to the State Department if and when the clause seems likely to become US law.

The gigantic Times-Mirror newspaper empire, Time-Life Inc. has also protested strongly against the Moynihan proposal

general will be increased in relation to the CNRS council, which will no longer make appointments and is renamed the council of administration. Claude Fresjacques remains president of CNRS and of this reduced council. One important power remains with the council, however: deciding the budget.

It is stressed at CNRS that there was no disagreement between Chevènement and the man Papon will succeed, Professor Jean-Jacques Payan. Although only ten months in his post, Payan has been enticed to a key job at the ministry of national education - where he will be responsible

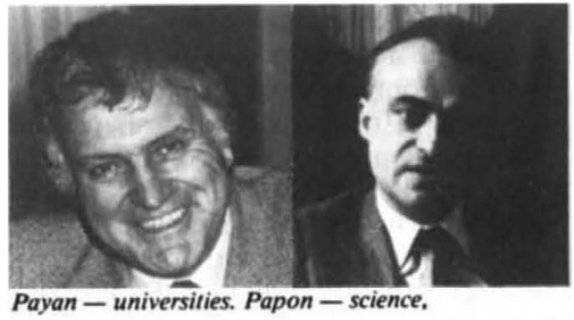

for universities and research. Payan's move, in fact, may help to strengthen Chevènement's hold on university research (which, except through the research councils such as CNRS, is strictly outside his control) insofar as Payan himself is a one-time Chevènement nominee (for the CNRS director-generalship).

Other reforms in CNRS announced include the establishment of new, partially elected committees to advise the scientific directors and the creation of two new scientific directorates, one for the application of CNRS results, and one for publications and popularization. The constitution is also changed to allow profitable liaisons to be made between laboratories and industry. The changes are closely in line with the "law for research" voted by the National Assembly earlier this year (Nature 8 July, p.110).

Robert Walgate 
Canada and yellow rain

\section{UN expert group asked to act}

fearing that the clause may be more destructive of US than of Canadian economic interests.

Moynihan's staff counters that the market for videotext and teletext is still so fluid in the United States that the big customers, who plan to use these systems to bring newspapers and news services into homes within a decade, can still choose the French or British system, that under development by AT\&T or some other.

The US Federal Communications Commission (FCC), which has the legal power to affect the outcome by developing standards for this new industry or by endorsing some industry-proposed standard, is standing aside. In October 1981 , FCC announced that the market should decide which systems were the best. The announcement, not yet a formal notice, heartened British Videotex and Teletex of New York, the company responsible for marketing Prestel in the United States. So long as FCC does not endorse a North American standard, Prestel still has a fighting chance. Senator Moynihan's clause would give it even a better one.

Deborah Shapley

\section{Washington}

This autumn will see a test of the United Nations' ability impartially to examine allegations of Soviet-inspired use of toxin weapons in South-East Asia. The Canadian government has submitted a report to the United Nations that gives credence to the charges and explains how they could be resolved. It will be up to the Group of Experts convened by the General Assembly to recommend to the Assembly whether or not to take up the report's suggestions. So far the Group of Experts has failed to reach any conclusion. The Soviet Union has denied that there is any toxin warfare in South-East Asia.

Canada has strongly supported the extension of the Group of Experts' mandate last year when its first investigation did not decide the matter. Refugees from Laos and Kampuchea say that helicopters and fixed-wing aircraft have been spraying poisonous gas that causes death to humans, animals and plants. If this is true, the Vietnamese, who

\section{Communication without compatibility}

None of the six main videotex standards is fully compatible with any other. Each offers a different solution to the central problem of balancing quality of display against the cost of the terminal.

At the cheap end of the scale are the systems with "alpha-mosaic" graphics, producing pictures on the screen with a crude building-block appearance. The memory of alpha-mosaic terminals stores a limited repertoire of basic mosaic shapes, from which an incoming byte of data can extract a particular shape and place it in a particular slot on the screen. The result, although inelegant, is economic in the use of memory and transmission bandwidth. But the description of information in the database is terminal-dependent.

"Alpha-geometric" systems specify pictures in terms of basic geometric figures and coordinates of a point on the screen. Almost any shape can be created and placed anywhere on the screen, while picture descriptions are not generally terminal-dependent. But greater memory and processor requirements raise the cost of such terminals.

The leading videotex systems have the following characteristics:

- Prestel: An alpha-mosaic standard established in 1974 by the British Post Office (now British Telecom) in cooperation with the broadcasting authorities BBC and IBA. Internationally, there are more Prestel-type terminals than others. Extended graphics capability is being developed.

- Antiope: The alpha-mosaic standard developed by the French tele- communications and broadcastign authorities (DGT and TDF).

- Telidon: The first alpha-geometric standard (produced by the Canadian Department of Communications) has attracted much attention for its superior display capability.

- $32 \times 16$ US alpha-mosaic: The central characteristic of this system -16 lines of 32 characters - is based on the low-cost Motorola VDG microchip. It has been adopted by US cable television and microprocessor manufacturers.

- CEPT: An attempt by the Association of European Telecommunications Administrations to establish a unified European alpha-mosaic standard. The standard can interpret data according to either the Prestel or the Antiope schemes, depending on the terminal.

- PLP: AT\&T's Presentation Level Protocol is not a standard in itself but is a vast package of options, from which AT\&T will select a subset to be included in a terminal for mass production. The range of capability of fered is so great that a comprehensive terminal would be of prohibitive cost. The importance of PLP is its flexibility and AT\&T's formidable powers for production and marketing. Other suppliers are willing to modify their standards to be compatible with PLP. The CEPT standard is compatible with the PLP alpha-mosaic subset, but is restrained from change because of the many videotex and teletex sets already in use in Europe. Discussions with AT\&T to modify its alpha-mosaic subset may prevent a permanent split between US and European standards. Bronwen Maddox are presumably flying the planes and helicopters, would be in violation of the 1925 Geneva Protocol prohibiting the use of poisons in warfare. If, as is suspected, the Soviet Union is the source of the toxin weapons, it is in violation of the 1972 Convention on Biological and Toxin Weapons.

Independently of its active role on the issue in the United Nations, the Canadian government commissioned its own study of the matter. In February it asked $\mathrm{Dr} \mathrm{H}$. Bruno Schiefer, chief of the toxicology group in the Western College of Veterinary Medicine at the University of Saskatchewan, to try and resolve the veracity of the charges. Dr Schiefer made a two-week visit to Thailand - neither he nor the Group of Experts were allowed into Laos or Kampuchea to check reports first-hand or take samples. Like the Group of Experts, Schiefer interviewed refugees through an interpreter and took samples from border areas near the sites of the alleged attacks.

Schiefer concluded that the events reported to have taken place at the time of the alleged attacks "cannot be explained on the basis of naturally occurring phenomena". He corroborates an assessment made by the US Department of State earlier this year that toxin warfare was Indeed being conducted there (see Nature 25 March, p291).

Schiefer first sought to resolve an apparent inconsistency. The poisons found in border areas, the particular tricothecene mycotoxins involved, act slowly and would have to occur in massive quantities to cause human death. Yet refugees seemed to say that clouds of "yellow gas" sprayed from the air caused death immediately. After close questioning of refugees, Schiefer concluded that the human deaths were not occurring immediately but that humans, animals and, plants in the vicinity were dying 10 to 14 days afterwards. This would be consistent with the level of poison reaching the ground in sprays.

Another problem has been that the tricothecene mycotoxins involved could not alone penetrate the human skin in such a fashion as to cause death. Schiefer began searching for possible agents that might be combined with the tricothecene to facilitate entry through the human skin. Because some of the refugees reported a garlic-like smell after the attacks, Schiefer suspects that dimethyl sulphoxide (DMSO) could be such an agent. The report suggests future field searches for DMSO and other possible agents.

The report also urges that a search should be made for the only known mycotoxin that could kill through ingestion, macrocyclic tricothecene, which thus would not need any additional agent to penetrate the skin. 